\title{
CONSTRUCTIONS FOR OPTIMIZATION \\ HEAT-INFLUENZED STATE CYLINDER MACHINE OF THE FIVE DIMENSIONAL DIESEL
}

\author{
A.V. Trynov, V.V. Korostychenko, R.Yu. Bugaytsov
}

The results of computational studies of the heat-stressed state of a cylinder sleeve of high-speed diesel have been presented. The research solves the problems of analyzing the influence of known constructive means, their combinations on the heatstressed state of the working surface of the sleeves. Optimization of the temperature of the state of the sleeve involves obtaining such a temperature profile along the working surface of the sleeve, which would provide the minimum friction costs, which in turn depends on the viscosity of the engine oil on the working surface of the sleeve. A mathematical model based on the finite element method is used.

\section{А.О. Прохоренко, С.С. Кравченко, І.М. Карягін, С.Г. Вовк, П.І. Думенко \\ РОЗРОБКА УНІВЕРСАЛЬНОГО ЕЛЕКТРОННОГО РЕГУЛЯТОРА ЧАСТОТИ ОБЕРТАННЯ КОЛІНЧАСТОГО ВАЛУ ДИЗЕЛЯ}

\begin{abstract}
Розроблено електронний регулятор паливної системи високого тиску для транспортного дизеля, впровадження якого дозволить формувати оптимальні характеристики транспортного засобу з урахуванням умов його експлуатації та узгодженості з будь-якими видами трансмісії та рушія. Авторами запропоновано коничепцію синтезу алгоритму електронного регулятора дизеля, який базується на аналогї з роботою механічного пружинно-важільного регулятора прямої дії. Проведені безмоторні та моторні дослідження паливного насосу високого тиску тракторного дизеля, обладнаного розробленим електронним регулятором, дозволили отримати його статичні (рівноважні) характеристики, які підтверджують працездатність та стійкість роботи системи.
\end{abstract}

\section{Вступ}

На більшості дизелів, що експлуатуються в Україні, використовуються системи паливоподачі 3 механічними регуляторами частоти обертання колінчастого валу. Дизелі, обладнані такою системою, мають ряд недоліків: невідповідність сучасним екологічним нормам, низький рівень паливної економічності, відсутність корекції паливоподачі в залежності від теплового стану двигуна і властивостей палива та окиснювача, наявність «просадки» моменту двигуна, викиди диму при розгоні та ін. Означені недоліки можуть вирішуватися шляхом застосування електронної системи регулювання паливоподачі.

Застосування електроніки в системах автоматичного регулювання та керування дозволяє істотно поліпшити показники паливної економічності та екологічності дизелів шляхом узгодження характеристик систем комбінованого двигуна, забезпечення їх роботи на оптимальних режимах, коригування законів керування в залежності від параметрів навколишнього середовища та властивостей палива.

Вартість електронних систем регулювання $\epsilon$ надзвичайно високою, а їх обслуговування та ремонт потребує наявності дорогого та складного обладнання i, відповідно, висококваліфікованого персоналу. Крім того, фірми-виробники зашифровують програмний алгоритм роботи регулятора, що унеможливлює коректування та налаштування його роботи, наприклад, при переобладнанні або доводці дизеля. Вищезгадане обумовлює актуальність розробки електронного регулятора дизеля на базі конструкції «класичного» паливного насосу.

Слід окремо відмітити, що створення подібних систем автоматичного регулювання потребує висококваліфікованих фахівців в галузях науки теорії двигунів внутрішнього згоряння, теорії автоматичного регулювання, алгоритмізації й низькорівневого програмування контролерів, радіоелектроніки тощо.

Метою роботи є розробка алгоритму та експериментального зразка універсального електронного регулятора частоти обертання колінчастого валу дизеля.

\section{Аналіз літератури}

Масове виробництво та обладнання дизелів паливною апаратурою з електронним керуванням $€$ монопольною прерогативою кількох провідних світових фірм - "Bosch", "Неinzmann” (Німеччина), "Delphi” (США), "Motorpal” (Чехія) та ін. Монопольне володіння вказаними технологіями дозволяє цим фірмам отримувати надприбутки, необгрунтовано завишаючи вартість як самих систем, так й робіт $з$ їх адаптації на об'єкті регулювання. Тому природно, що вказані фірми-виробники не видають жодної інформації про склад, структуру алгоритмів та програм, за якими працює їх обладнання. Такого ж підходу до ведення бізнесу притримуються й невеликі приватні фірми, які займаються переобладнанням традиційної паливної апаратури на електронне керування. Тобто відкриті публікації у закордонних джерелах за даним питанням відсутні. На- 
томість, вітчизняні вчені приділяють роботі зі створення електронних регуляторів дизелів багато уваги [1-10]. Слід відмітити роботи у даному напрямку проф. А.Ф. Головчука, проф. А.А. Лісовала, проф. О.Б. Богаєвського та ін. Так, роботи [6-8] направлені на створення ефективних систем електронного керування тепловозних дизелів, алгоритми яких не можуть бути використані для машин наземного транспорту в силу особливостей їх експлуатації. В роботах $[1,2]$ розроблявся електронний регулятор для тракторного дизеля з приводом рейки шаговим двигуном, але для розрахунку величини циклової подачі палива (регулюючого впливу) використовувався алгоритм на основі табличної інтерполяції, що накладає додаткові вимоги до апаратних ресурсів, ускладнює та уповільнює виконання команд програмного коду. Роботи [3-5] направлені на застосування та вдосконалення ПІДрегулювання, а підхід до організації всережимного алгоритму такий, як сказано вище.

\section{Виклад основного матеріалу дослідження}

Для управління рейкою паливного насосу високого тиску запропоновано підхід до синтезу алгоритму електронного регулятора, який базується на аналогії з роботою механічного пружинноважільного регулятора прямої дії. Саме такими регуляторами обладнана більшість дизелів, що знаходяться в експлуатації. Механічні всережимні регулятори дизелів забезпечують прийнятні (але - не оптимальні) експлуатаційні регуляторні характеристики та $є$ достатньо надійними агрегатами.

Нова гіпотеза авторів 3 цього приводу така: переміщення регулюючого органа (величина регулюючого впливу) $H p$ позитивно залежить від положення органа керування паливоподачею $X$, та негативно - від поточної частоти обертання (кутової швидкості) колінчастого валу $n$, що можна описати формулою

$$
H p=A_{1}+A \cdot X-B \cdot n,
$$

де $A_{1}, A$ та $B$ - сталі (або змінні) коефіцієнти.

Використання запропонованого алгоритму створює пряму аналогію з кінематикою механічного всережимного регулятора частоти обертання дизеля зі змінним затягуванням пружини, що проілюстровано схемою на рис. 1. Як видно, при цьому величина $\Delta X$ характеризує переміщення важеля управління 7 (т. Е), доданок $B \cdot \Delta n-$ положення муфти регулятора 3 , на яку діє відцентрова сила вантажів (т. В), тоді величина $\Delta H p$ - це однозначне положення рейки ПНВТ 6 (т. D).

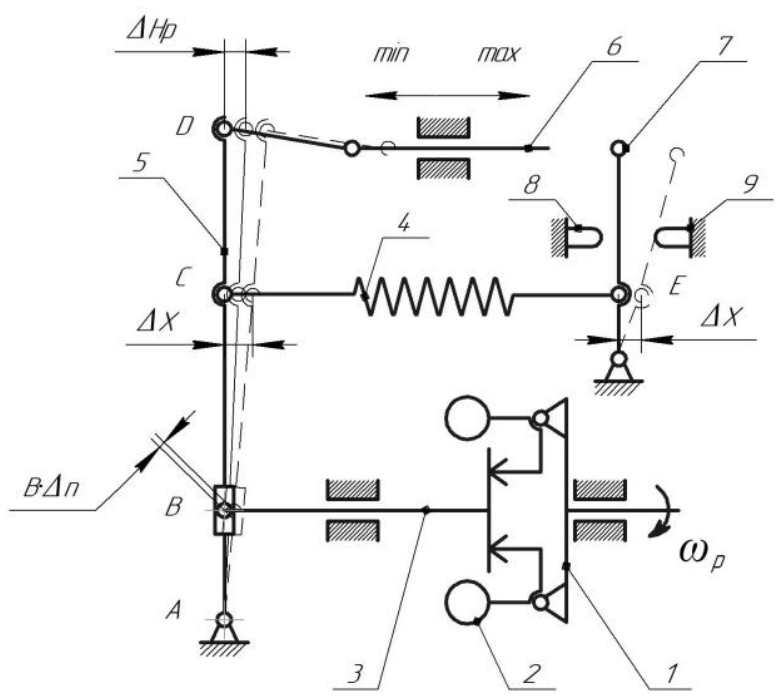

Рис. 1. Принципова схема механічного всережимного регулятора: 1 - чутливий елемент; 2 - вантажі чутливого елементу; 3 -муфта регулятору;

4 - пружина регулятору холостого ходу; 5 - важіль регулятору; 6 - рейка ПНВТ; 7 - важіль

управління; 8 - упор $\omega_{\min } ; 9-$ упор $\omega_{\max }$.

Коефіцієнти $A_{1}, A$ і $B$ в формулі (1) характеризують відношення плечей $\mathrm{AD}, \mathrm{AC}$ i $\mathrm{AB}$ важеля регулятора 5. Величина цих коефіцієнтів визначається виходячи із заданого ступеня нерівномірності, коефіцієнта пристосовності і максимально допустимої частоти обертання. Тобто, підбором даних коефіцієнтів можна забезпечити потрібний вигляд (уклін) регуляторних характеристик, або, іншими словами, універсальної характеристики дизеля. Приклад синтезу такої характеристики з використанням коефіцієнтів $A_{1}=3,1, A=7,6, B=0,0044$ наведено на рис.2.

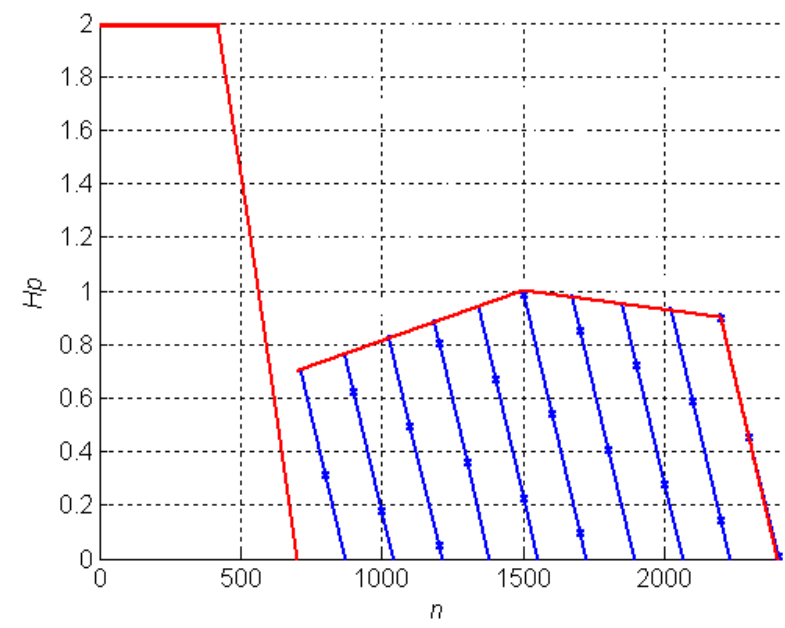

Рис. 2. Регуляторні характеристики паливного насосу високого тиску, щзо забезпечуються запропонованим алгоритмом 
Таким чином, без внесення будь-яких конструктивних змін у паливну апаратуру або регулятор можливо узгодити характеристики двигуна для отримання потрібних експлуатаційних характеристик транспортного засобу (наземної машини). Важливо, що такий самий підхід (на основі наведеної формули (1)) можна використовувати й для синтезу алгоритму електронного регулятора для акумуляторної системи паливоподачі 3 електрогідравлічним впорскуванням.

Функціональна схема електронного регулятора частоти обертання колінчастого валу наведена на рис. 3.

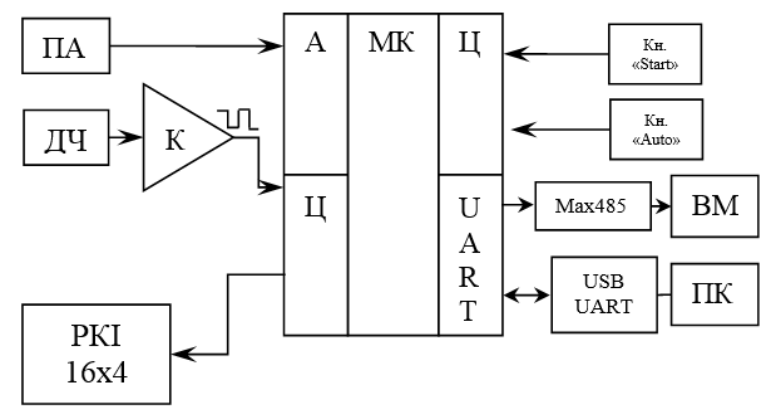

Рис. 3. Функціональна схема електронного регулятора частоти обертання колінчастого валу:

ПА - педаль акселератора; ДЧ - датчик частоти обертання колінчастого валу; $K$ - компаратор; PКI-рідиннокристальний індикатор; $М К$-мікроконтролер; $А$ - анаголовий вхід; Ц - ичирові входи/виходи; Кн «Start»-кнопка запуску/зупинки двигуна; Кн «Аиtо» - кнопка включення однорежимного регулятора; Мах485 - передатчик; ВM - виконавчий механізм; UART - інтерфейс послідовного обміну; USB-UART-перетворювач інтерфейсів

Основою системи електронного регулятора $\epsilon$ електронний блок управління на мікроконтролері ATmega328, виконавчий механізм, датчики положення педалі акселератора та частоти обертання колінчастого валу.

В якості виконавчого механізму для приводу рейки паливного насосу використано актуатор, що розроблений фірмою «DigasGroup» (Латвія).

Датчик педалі акселерометра реєструє переміщення педалі управління і передає відповідний сигнал в електронний блок керування (ЕБК). Основна складова частина цього датчика - потенціометр, 3 якого реєструється напруга, що залежить від положення педалі управління. За допомогою завантаженого в ЕБК характеристик датчика, напруга перетвориться в відносне переміщення положення педалі.
Частота обертання колінчастого валу розраховується за часом періоду сигналів індуктивного датчика, що змонтований безпосередньо навпроти закріпленого на колінчастому валу маховика, на якому закріплена феромагнітна пластина. При обертанні колінчастого валу пластина, проходячи в безпосередній близькості від датчика, наводить в котушці ЕРС, що отримується в синусоїдальній вихідній напрузі. Встановлений компаратор перетворює вихідну напругу з імпульсами синусоїдальної форми зі змінною амплітудою в напругу з імпульсами прямокутної форми 3 постійною амплітудою. Дані сигнали обробляються мікроконтролером в ЕБК.

Мікроконтролер перетворює та обробляє первинну інформацію, що надходить від датчиків частоти обертання двигуна, положення педалі акселератора, кнопок «Start» та «Auto», реалізує закладений алгоритм управління. За результатами обробки цих сигналів мікроконтролер реагує на них через виконавчий механізм.

Зв'язок мікроконтролера 3 виконавчим механізмом виконаний через протокол передачі даних MAX-485.

ЕБК управління має перетворювач інтерфейсів USB-UART на мікроконтролері ATmega16U2. За допомогою перетворювача здійснюється USB підключення $з$ персональним комп'ютером для перепрограмування.

В якості інтерфейса використано чотиристроковий 16-ти символьний рідиннокристальний індикатор, на який виводиться необхідна інформація: поточна та задана (при роботі однорежимного регулятора) частота обертання колінчастого валу, відносне положення рейки паливного насосу та педалі акселератора, режим роботи регулятора та ін.

Даний електронний регулятор не потребує значної зміни конструкції паливного насосу, є гнучким у налаштуванні та універсальним, може встановлюватися на різні типи дизелів.

Для перевірки працездатності розробленого алгоритму та функціональної схеми електронного регулятора частоти обертання колінчастого валу в науково-дослідній лабораторії кафедри двигунів внутрішнього згоряння НТУ «ХПІ» було проведено безмоторні та моторні експериментальні дослідження.

На рис. 4 наведені експериментальні статичні характеристики дослідного електронного регулятора ПНВТ при всережимному регулюванні. 


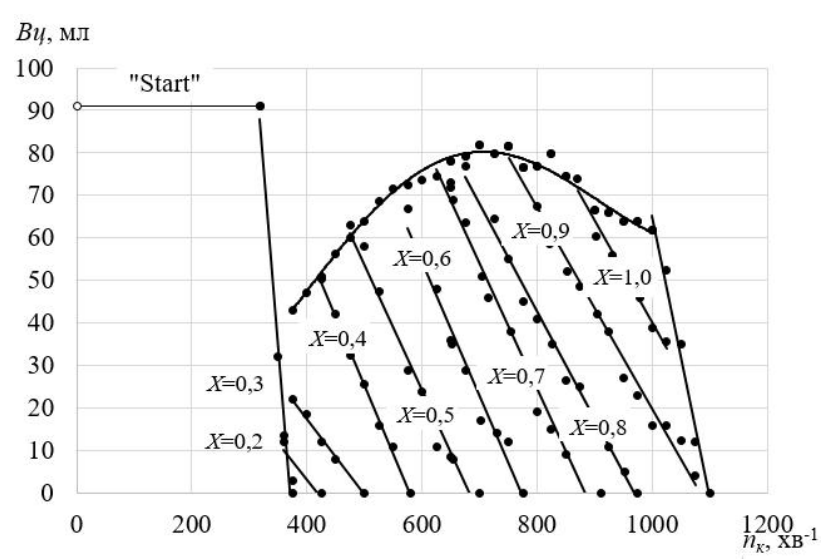

Рис. 4. Зовнішня та часткові характеристики ПНВТ з дослідним електронним регулятором при всережимному регулюванні (статичні характери-

\section{стики)}

Розроблений універсальний електронний регулятор частоти обертання колінчастого валу дизеля використовується на кафедрі ДВЗ НТУ «ХПІ» для керування роботою одноциліндрового дослідницького відсіку дизеля ЧН12/14.

Проведені моторні дослідження на одноциліндровому відсіку Ч12/14 при статичному регулюванні на усталеному режимі показали, що значно підвищується стабільність частоти обертання колінчастого валу дизеля $\left(\Delta n= \pm 2 \mathrm{xв}^{-1}\right)$ незалежно від якості пального, технічного стану двигуна, умов довкілля тощо. Крім того, застосування запропонованого електронного регулятору на дизелях дозволить суттєво зменшить час плину перехідного процесу та покращити експлуатаційні характеристики дизеля.

\section{Висновки}

1. Запропоновано та реалізовано синтез алгоритму електронного регулятора дизеля, який базується на аналогії з роботою механічного пружинноважільного регулятора прямої дії.

2. Розроблено функціональну схему та експериментальний зразок електронного регулятору частоти обертання колінчастого валу дизеля.

3. Проведені безмоторні та моторні дослідження паливного насосу високого тиску тракторного дизеля, обладнаного електронним регулятором, дозволили отримати його статичні (рівноважні) характеристики які підтверджують працездатність та стійкість роботи системи.

Автори виражають щиру подяку фірмі «DigasGroup» (Латвія) за наданий виконавчий механізм, що в суттєво допомогло реалізувати запропоновані функціональну схему та алгоритм електронного регулятора.

\section{Сиисок літератури:}

1. Головчук А.Ф. Універсальний електронний регулятор для тракторного дизеля / А.Ф. Головчук, Ю.Ш. Гарбієль // Двигатели внутреннего сгорания. - 2014. - №1. - С. 3134. 2. Головчук А. Електронний регулятор паливоподачі дизеля / А. Головчук, Ю.Габрієль, В. Жолобко // Проблеми з транспортними потоками і напрями їх розв'язання : збірник наукових праць : тези доповідей всеукрайнськоі науково-теоретичної конферениі / Національний університет «Львівська політехніка», - Львів : Видавництво Львівської політехніки, 2015. - С. 126. 3. Лисовал А.А. Микропроцессорный регулятор дизеля и расчёт иикловой подачи топлива / А.А. Лисовал, С.В. Кострица, А.В. Вербовский // Двигатели внутреннего сгорания. - 2010. - № 2. - С.58-61. 4. Лисовал А.А. Методика и результаты испьтания микропрочессорного регулятора с программно- измерительным комплексом в его составе / А.А. Лисовал // Двигатели внутреннего сгорания. - 2007. - № 1. - С. 15-19. 5. Лисовал А.А. Всережимный электронный регулятор дизеля колесного транспортного средства / А.А. Лисовал, А.В. Вербовский // Двигатели внутреннего сгорания. - 2012. - № 1. - С. 49-52. 6. Богаевский А.Б. Компьютерная модель мощчного транспортного дизельгенератора с электронной системой управления./ А.Б. Богаевский // Открытые информационные и компьютерные интегральные технологии. - 2008.- Вып. 38. - C. 150 - 169. 7. Богаевский А.Б. Исследование влияния технических средств управления на повышение эксплуатаиионной экономичности маневрового тепловоза / А.Б. Богаевский, А.В. Осичев, М.С. Войтенко // Вісник СНУ ім. В. Даля. - 2013. - № 18(207). Ч.2. - С. 177 - 182. 8. Богаевский А.Б. Оиенка возможности снижения расхода топлива дизель - генератора маневрового тепловоза за счет совершенствования управления / А.Б. Богаевский, А.М. Борисенко, М.С. Войтенко // Двигатели внутреннего сгорания. - 2013. - № 1. - С. 105-109. 9. Марков В. А. Система топливоподачи с электронным управлением тепловозного дизеля / В. А. Марков, В. В. Фурман, В. С. Акимов // Изв. вузов. Машиностроение. - 2013. - № 7. C. 60-65. 10. Александрова Т.С. Електронний регулятор паливоподавання транспортного дизеля з нерегульованим турбонаддувом // Труды Одесского государственного политехнического университета. - 2001. - Bbin. 5. C. 192-195.

\section{Bibliography (transliterated):}

1. Golovchuk, A.F., Garbicl', Ju.Sh. (2014), Universal electronic regulator for tractor diesel [Universal'nij elektronnij reguljator dlja traktornogo dizelja], Internal Combustion Engines, No. 1, pp. 31-34. 2. Golovchuk, A., Gabricl', Ju., Zholobko, V. (2015), Electric diesel injection controller [Elektronnij reguljator palivopodachi dizelja], Problems with transport streams and directions of their solution: $a$ collection of scientific works: abstracts of reports of the AllUkrainian scientific and theoretical conference / National University "Lviv Polytechnic", P.126. 3. Lisoval, A.A., Kostrica, S.V., Verbovskij, A.V. (2010), Microprocessor diesel controller and calculation of cyclic fuel supply, [Mikroprocessornyj reguljator dizelja i raschjot ciklovoj podachi topliva], Internal Combustion Engines, No. 2, pp. 58-61. 4. Lisoval, A.A. (2007), The procedure and results of a test of a microprocessor controller with a program-measuring complex in its composition, [Metodika i rezul'taty ispytanija mikroprocessornogo reguljatora s programmno-izmeritel'nym kompleksom v ego sostave], Internal Combustion Engines, No. 1, pp. 15-19. 5. Lisoval, A.A., Verbovskij, A.V. (2012), All-regime electronic diesel engine of the wheeled vehicle, [Vserezhimnyj jelektronnyj reguljator dizelja kolesnogo transportnogo sredstva], Internal Combustion Engines, No. 1, pp. 49-52. 6. Bogaevskij, A. B. (2008), Computer model of a powerful transport diesel generator with electronic control system, [Komp'juternaja model' moshhnogo transportnogo dizel'-generatora s jelektronnoj sistemoj upravlenija], Open infor- 
mation and computer integrated technologies, Issue 38, pp. 150-169. 7. Bogaevskij, A.B., Osichev, A.V., Vojtenko, M.S. (2013), Investigation of the influence of technical controls on increasing the operational efficiency of the shunting locomotive, [Issledovanie vlijanija tehnicheskih sredstv upravlenija na povyshenie jekspluatacionnoj jekonomichnosti manevrovogo teplovoza], Bulletin of the Volodymyr Dahl East-Ukrainian National University, № 18 (207), part 2, pp. 177-182. 8. Bogaevskij, A.B., Borisenko, A.M., Vojtenko, M.S. (2013), Estimation of the possibility of reducing the fuel consumption of the diesel generator of the shunting locomotive due to improved control, [Ocenka vozmozhnosti snizhenija rashoda topliva dizel'- generatora manevrovogo teplovoza za schet sovershenstvovanija upravlenija], Internal Combustion Engines, No. 1, pp. 105-109. 9. Markov, V. A., Furman, V. V., Akimov, V. S. (2013), Fuel supply system with electronic diesel engine control, [Sistema toplivopodachi s jelektronnym upravleniem teplovoznogo dizelja], Mechanical engineering, № 7, pp. 60-65. 10. Alexandrova, T.E. (2001), Electronic regulator of fuel supply of a transport diesel with unregulated turbocharging, [Elektronnij reguljator palivopodavannja transportnogo dizelja z neregul'ovanim turbonadduvom], Proceedings of the Odessa State Polytechnic University, Issue 5, pp. 192-195.

Надійшла до редакиії 10.07.2017 p

\title{
РАЗРАБОТКА УНИВЕРСАЛЬНОГО ЭЛЕКТРОННОГО РЕГУЛЯТОРА ЧАСТОТЫ ВРАЩЕНИЯ КОЛЕНЧАТОГО ВАЛА ДИЗЕЛЯ
}

\section{А.А. Прохоренко, С.С. Кравченко, И.Н. Карягин, Е.Г. Вовк, П.И. Думенко}

Разработан электронный регулятор топливной системы высокого давления для транспортного дизеля, внедрение которого позволит формировать оптимальные характеристики транспортного средства с учетом условий его эксплуатации и согласованности с любыми видами трансмиссии и двигателя. Авторами предложена концепция синтеза алгоритма электронного регулятора дизеля, основанного на аналогии с работой механического пружинно-рычажного регулятора прямого действия. Проведенные безмоторные и моторные исследования топливного насоса высокого давления тракторного дизеля, оснащенного разработанным электронным регулятором, позволили получить его статические (равновесные) характеристики, подтверждающие работоспособность и устойчивость работы системы.

\section{DEVELOPMENT OF THE UNIVERSAL ELECTRONIC REGULATOR ROTATION OF THE CRANKSHAFT OF DIESEL}

\section{A.A. Prokhorenko, S.S. Kravchenko, I.N. Karyagin, E.G. Vovk, P.I Dumenko}

An electronic regulator of a high-pressure fuel system for a transport diesel has been developed, the introduction of which will allow to formulate optimal characteristics of a vehicle taking into account the conditions of its operation and coherence with any types of transmission and engine. The authors suggested the concept of synthesis of the algorithm of the electronic diesel controller, based on the analogy with the operation of a mechanical spring-lever regulator of direct action. Carried out motorless and motor studies of a high-pressure fuel pump of a tractor diesel engine equipped with a developed electronic regulator, it was possible to obtain its static (equilibrium) characteristics, confirming the operability and stability of the system.

Прохоренко Андрій Олексійович - доктор техн. наук, проф., професор кафедри двигунів внутрішнього згоряння Національного технічного університету «Харківський політехнічний інститут», Харків, Україна. е-таil: ap.kharkiv@ukr.net.

Кравченко Сергій Сергійович - канд. техн. наук, молодший науковий співробітник кафедри двигунів внутрішнього згоряння Національного технічного університету «Харківський політехнічний інститут», Харків, Україна, е-таil: kravc4enkoserg@gmail.com.

Карягін Ігор Миколайович - старший науковий співробітник кафедри двигунів внутрішнього згоряння Національного технічного університету «Харківський політехнічний інститут», Харків, Україна, e-mail: karyaginin@gmail.com

Вовк Свгеній Геннадійович - аспірант кафедри двигуни внутрішнього згоряння Харківського національного автомобільно-дорожнього університету, Харків, Україна, e-mail: jake_vovK@ukr.net.

Думенко Петро Іванович - директор SIA «Digas», м. Рига, Латвійська Республіка, e-mail: p.dumenko@digasgroup.com.

\section{Р. Ариан, Х. Хотейт, И.А. Мордвинцева, О.Ю. Линьков, В.А. Пылев}

\section{ВЛИЯНИЕ ВЫБОРОК В ЗОНЕ КРОМКИ КАМЕРЫ СГОРАНИЯ ПОРШНЯ НА ЕГО ТЕПЛОНАПРЯЖЕННОСТЬ И РЕСУРС ПО ПРОЧНОСТИ}

\begin{abstract}
Представлен анализ основных характерных повреждений пориней двигателей внутреннего сгорания, последуюших отказов и причин, их вызывающих. Показано, что на сегодня имеют место случаи нарушения коничепции гарантированного обеспечения ресурса пориня на стадии его проектирования. Рассмотрень варианты формоизменения кромок камер сгорания пориней дизеля 4ЧН12/14. Применительно к условиям эксплуатации автомобильного и тракторного дизелей оценены границы ресурсной прочности альтернативных вариантов кромок камер сгорания.
\end{abstract}

\section{Введение}

Обеспечение заданного ресурса теплонапряженных деталей камеры сгорания (КС) в условиях постоянного роста уровня форсирования двигателей является сложной научно-технической задачей. При этом существенное внимание уделяется оцен- 